\title{
IMPROVEMENT OF A DISTRIBUTION NETWORK OF A DIRECT SALE COSMETICS SUPPLY CHAIN
}

\author{
Diez, M. ${ }^{*}$; Mula, J. ${ }^{* *} \&$ Campuzano-Bolarin, F. ${ }^{* * *}$ \\ * Coordinador de Logística, Amcor Rigid Plastics Ecuador S.A., \\ Km. 4 Vía Perimetral y Ave Fco. de Orellana S/N, Guayaquil, Ecuador \\ ${ }^{* *}$ CIGIP (Research Centre on Production Management and Engineering), \\ Universitat Politècnica de València, Plaza Ferrándiz y Carbonell, 2, 03801, Alcoy, Alicante, Spain \\ *** Business Management Department, Universidad Politécnica de Cartagena, \\ Campus Muralla del Mar, s/n, 30202, Cartagena, Murcia, Spain \\ E-Mail:marco.diez@amcor.com,fmula@cigip.upv.es, francisco.campuzano@upct.es
}

\begin{abstract}
Consistent studies assessing the impact of the strategic decision of distribution nodes with no-financial key performance indicators are lacking. This work focuses on studying how the distribution system of a direct sale cosmetics supply chain behaves and on generating decision-making scenarios relating to the definition and size of distribution nodes. A systems dynamics-based simulation tool deals with a strategic decision and size of distribution nodes in a reduced direct sale supply chain of cosmetic products. The methodological approach presented herein allows to analyse how existing facilities operate and to verify their performance. Finally, this work provides a reference conceptual model for the strategic definition of distribution nodes.

(Received in October 2012, accepted in June 2013. This paper was with the authors 3 months for 3 revisions.)
\end{abstract}

Key Words: Supply Chain Management, Distribution Management, Logistics, Simulation

\section{INTRODUCTION}

In recent decades, the way firms operate is no longer individual as they now undertake their operations according to a supply chain outline, whose success depends on the efficiency with which their managers and directors can integrate firm-firm operations while making full use of the synergy generated in their inter- and intra-firm relations [1]. From these activities, logistic operations derive since it is a critical system in which firms focus on improving the service level they offer their clients while controlling incurred costs at the same time.

Simulating a system consists in building a model that represents it completely or partially which, when run, reflects the real system's behaviour. This practice enables us to study complex system interactions and to explain how the system affects their behaviour. In running a dynamic model, the simulation objectives are to: assess the various production systems' configurations; develop and validate improvements; reproduce and attempt decision alternatives; quantify profits; and support decision making. In addition, the systems dynamics in $[2,3]$ allows us to analyse the system's structure and, based on this study, a dynamic system can be built which reproduces this system's behaviour. In this specific case, it is an alternative to help deal with a critical aspect; problems of defining distribution nodes in the supply chain.

Decision making in relation to the distribution system design is a strategic aspect for the vast majority of firms. Where to locate facilities, particularly distribution nodes, and where to allocate demand to these facilities are priorities when the distribution network is being designed. Decisions on where to locate facilities are made by considering the long term, use of warehouses, distribution centres and transit warehouses, although their defining factors vary over time. Variables such as demand (volume, regional distribution) and structure costs 
change, and relocation or redesigning facilities can prove costly. Therefore, dynamic models are developed which generate system behaviour and provide scenarios for decision making [4].

The objective of this work is to deal with the strategic decision and size of distribution nodes in a reduced direct sale cosmetics supply chain through a systems dynamics-based simulation model. With data on variables such as demand level, delivery times, fleet capacity, closeness among demand points and resources allocation, among others, the intention is to gain a better understanding of the system and, by means of a what-if analysis, to know the system's behaviour when faced with different variations over time. Therefore depending on the initial definitions, it is possible to analyse how existing facilities operate and to verify their performance. Furthermore, this work provides a reference model for the distribution nodes' strategic definition.

This work continues in Section 2 with a literature review of the systems dynamics simulation models in the supply chain context. Section 3 describes the supply chain and the logistics system, which are the object of this case study. Section 4 describes the simulation model construction. Section 5 offers details of the relevant results obtained with the simulations carried out. Finally, Section 6 provides the conclusions drawn and future research lines.

\section{LITERATURE REVIEW}

Although the literature in this domain is very extensive, this section contemplates some works closely related to the study objective. In accordance with the modelling approach, defined by the nature of the input data and the study objectives, Beamon [5] divided the supply chain design and analysis models into four categories: analytical deterministic models, analytical stochastic models, economic models and simulation models. In the analytical models context, industrial software solutions, such as APS (Advanced Planning Systems) (Stadtler and Kilger [6]), are different tools which came to maturity in parallel to ERP (enterprise resource planning) systems to optimise supply chain production decisions.

Relations among the firms throughout the supply chain make it difficult to know the level of impact that certain changes or poor performances within the chain may have. Thus, it is necessary to rely on a tool that makes the whole chain visible and allows tests to be done with what-if scenarios, which can be run with simulation models [7]. Simulation provides firms with a perspective on supply chain dynamics and its efficacy [8]. Simulating a supply chain implies a behaviour that integrates logistic and production networks which represent complex inter- and intra-organisational facilities characteristics, physical entities and resources [9-11]. In supply chain simulation, some studies about bullwhip avoidance techniques are found in Cannella et al. [12-15].

Rabelo et al. [16] develop a hybrid simulation model by combining discrete event simulation and the systems dynamics methodology. This was used to model an organisation's general system from the strategic and tactical viewpoints, whereas discrete event simulation was employed to model production functions and operational tasks relating to facilities.

For distribution network management, the work by Lim and Shiode [17] is relevant, which is based on a discrete event simulation approach to evaluate the impact of different scenarios in order to increase online shopping demand by considering strategic, tactical and operational decision levels. Bozickovic et al. [18] integrate discrete event simulation tools and lean concepts to analyse production systems. Calderon and Lario [19] analyse 40 articles published between 2002 and 2006 to complement that done by [10]. Their article evidences that publications which analyse supply chain simulation significantly contribute to cut delivery times, minimise inventories, enhance flexibility, improve trust; the stages they cover are 
production and distribution, transport, distribution centres, retailers; and the simulated processes are demand forecasts, reception of orders, distribution and transport.

In the business domain, systems dynamics has made contributions in several subfields: administration, operations, organisational performance, marketing, and behaviour for making decisions and strategies [20]. Systems dynamics applications are of much interest for the strategy field as they help generally improve the performance of organisations because their decision-making processes are correctly managed. Campuzano et al. [21] present a systems dynamics model with estimated fuzzy demand to analyse the bullwhip effect and to extend inventory variance. Campuzano and Mula [22] demonstrate how to simulate a multi-level supply chain by following the systems dynamics methodology. Emphasis is placed on systems dynamics finding the critical variables of a complex system and on identifying the causal links among them.

In relation to the previous literature, supply chain simulation has increased and, specifically, the use of systems dynamics in supply chain modelling has augmented given the complexity of its relations. The dynamic nature and behaviour of the supply chain depend on, among others, clients' demand uncertainty, relations with suppliers and the logistic system [23]. Furthermore, this method is used to study not only the flexibility and capacity of the system's reaction being represented, which offers managers and directors the option to consider, study and assess possible solutions, but also the impact of its application when amending the system's operation [24]. It is applied in supply chains given its potential to generate and aggregate information about the system's dynamic behaviour. Systems dynamics centres on the interaction among the physical processes, information flows and management policies governing the system. As a whole, these relations define the structure of the system to be dealt with. In this paper, supply chain simulation based on systems dynamics is used for improving performance in a real world supply chain.

\section{CASE STUDY DESCRIPTION}

This work has been carried out in a direct sale supply chain of cosmetics and personal hygiene products. It is considered a reduced supply chain strategy and involves a supply chain with a small number of echelons for improving supply chain dynamics [25].

The chain is made up of suppliers, manufacturer and clients. Replenishment is covered by local and international suppliers of raw materials, consumables and finished products. In this sense, Bronja [26] proposes a multi-criteria approach for ranking suppliers in the supply chain context. The manufacturer is a firm which produces cosmetic and personal hygiene products. The production programme and the respective orders of raw materials and consumables are placed in the respective distribution centres' warehouses. The distribution centres are the manufacturer's facilities. They carry out activities such as storage and handling of finished products, as well as preparing and dispatching orders. All the areas undertaking the aforementioned activities are now briefly explained.

The warehouses area is in charge of receiving, handling and storing finished products (local production and purchases to subsidiaries), controlling inventories and managing product replenishment orders which the area preparing orders generates (Picking).

The picking area creates and sends replenishment orders of finished products to the warehouses area. It prepares orders according to the orders received weekly from clients.

The dispatching area is based on a dispatching schedule. Orders, which are prepared in the picking area, are dispatched nationally. Here the logistic system begins to distribute orders to clients.

On a weekly basis, clients send orders over a web site in accordance with an invoicing schedule divided into commercial zones, with a specific day of the week assigned for this 
very purpose. Their orders are delivered during a 48-hour period at the most after their commercial zone's invoicing has finished. Order promising and quality service are factors that generate client fidelity and are, therefore, highly differentiated from the firm's competitors.

According to Hwang [27], a logistic system consists in a series of clients, their location and what their demand amounts to, and in warehouses or distribution centres with their respective service capacity. The elements making up the supply chain's logistic system, which is the object of this work, are provided below.

Distribution nodes are all the facilities making up the distribution system which facilitate the flow of products to the demand points, and whose operation considers service level a critical factor. The nodes intervening in the distribution network of this particular chain are:

- Distribution Centre (DC). It is the only national DC. The Dispatching Area receives orders from the Picking Area to be dispatched to the Logistic Centres (LCs) and transit warehouses by means of a manual orders dispatching process, which involves operational classification activities, barcode readings, and emitting documents to support the transport to the distribution zones or directly to clients.

- Logistic Centres (LCs). The system has four LCs placed in various locations that differ from those of the DCs. These LCs are in charge of a Distribution Zone and its respective transit warehouses. The orders dispatching process is run (barcode readings and emitting documents to support transport) to dispatch orders for last mile distribution.

- Transit Warehouses (TWs). These include ten facilities used to swiftly receive and dispatch the orders allocated to an LC depending on its proximity. Their operations last short periods during which order classification activities are performed by distribution service suppliers.

- Distribution Zone (DZ). It is managed by an LC and is in charge of operating the TWs and the respective distribution fleet. The system is composed of four DZs. Fig. 1 depicts the location of the nodes and their respective DZs, while Fig. 2 shows the materials and information flows, including the travel times among the DCs and the nodes in each zone. Table I provides details about the distances and travel times between the DCs and the system nodes.

- Distribution route (DR). Each distribution route relates with a quantity of orders. A DZ can be formed by one or several DRs. Each DR is allocated its respective distribution fleet for last mile delivery.

- Transport and Distribution Fleet. The transport service between the DC to the LCs and the TWs is the responsibility of heavy transport suppliers. Last mile distribution is carried out by door-to-door delivery suppliers. Table II indicates some relevant information about the nodes' distribution fleet, and distinguishes between urban and peripheral delivery zones.

Table III indicates the most relevant activities carried out in each node, distinguished as node type, LC and TW, and also as those in which the personnel works (dispatch auxiliaries).

In the current situation, the definition and size of LCs and TWs were empirically decided without using any formal analysis and validation tool. The decisions made on the logistic system are considered to be decisive in nature given the impact that their operation has on the client-perceived service level. The on time delivery of all the orders $(100 \%)$ is considered a strategic objective and its importance lies in it being one of the main advantages that distinguish the firm from its competitors.

Product variety is considered in relation to prepared orders; e.g., a set of items whose quantity varies depending on the week. On average, there are between 22 and 31 items per order. These items are divided into four types of packing box depending on the size. This means that an Operational Area is required for their location and their load capacity on vehicles. The orders are included in the model from total demand. 


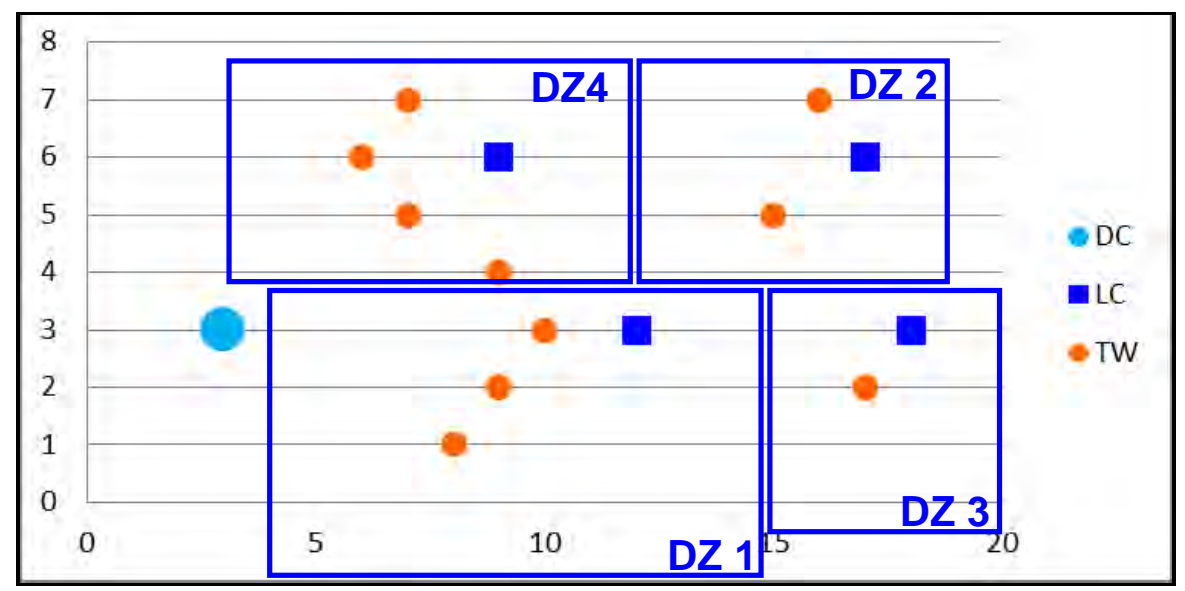

Figure 1: Location of nodes in the distribution network.

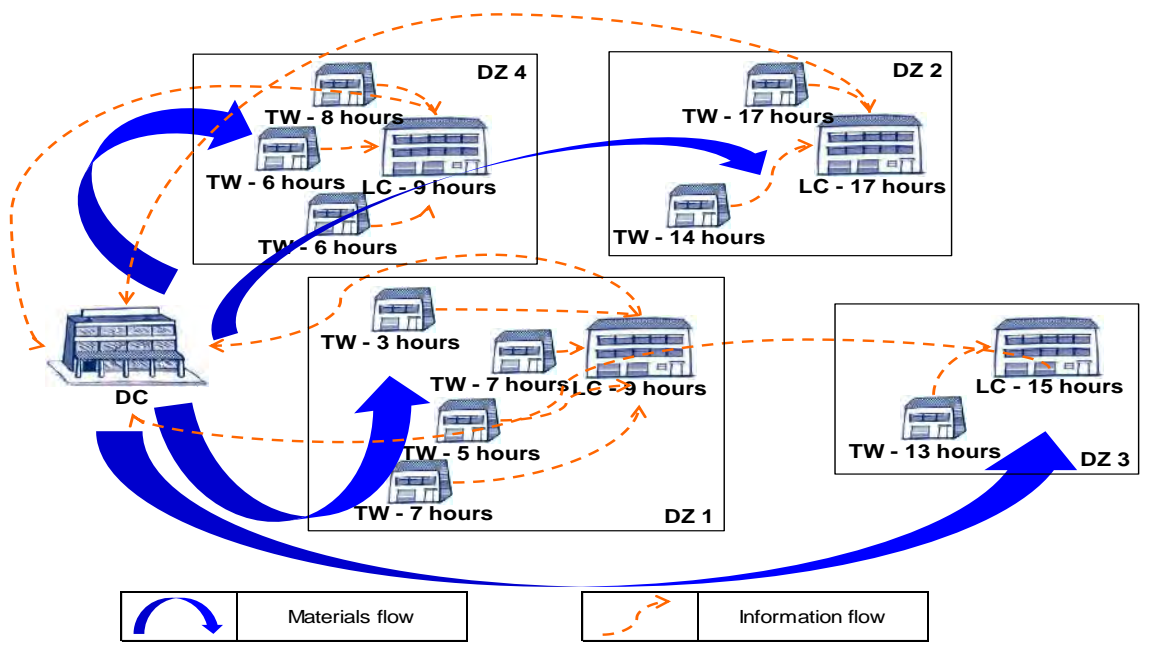

Figure 2: Materials and information flows between distribution nodes.

Table I: Distances and travel time between DC and nodes.

\begin{tabular}{|c|c|c|c|c|}
\hline Origin & $\begin{array}{c}\text { Distribution } \\
\text { zone }\end{array}$ & Node & $\begin{array}{l}\text { Travel time } \\
\text { (hours) }\end{array}$ & $\begin{array}{c}\text { Distance } \\
(\mathrm{km})\end{array}$ \\
\hline \multirow{14}{*}{$\begin{array}{l}\text { Distribution centre } \\
\text { (DC) }\end{array}$} & \multirow{5}{*}{ DZ1 } & LC1 & 9 & 375 \\
\hline & & TW1 & 5 & 208 \\
\hline & & TW2 & 7 & 292 \\
\hline & & TW3 & 7 & 292 \\
\hline & & TW4 & 3 & 125 \\
\hline & \multirow{3}{*}{ DZ2 } & LC2 & 17 & 708 \\
\hline & & TW5 & 14 & 583 \\
\hline & & TW6 & 17 & 708 \\
\hline & \multirow{2}{*}{ DZ3 } & LC3 & 15 & 625 \\
\hline & & TW7 & 13 & 542 \\
\hline & \multirow{4}{*}{ DZ4 } & LC4 & 9 & 375 \\
\hline & & TW8 & 6 & 250 \\
\hline & & TW9 & 8 & 333 \\
\hline & & TW10 & 6 & 250 \\
\hline
\end{tabular}

This work develops a system dynamics-based simulation model which enables the consideration of new node requirements by understanding the interaction of certain variables and the way that they influence distribution network behaviour. It also serves to assess 
existing nodes, to detect to what extent these adapt to current demands, and to propose improvements or future definitions in accordance with growth in demand levels. The decisions in this area are made by considering the long term. A correct preliminary definition of the facilities can avoid having to make short- or mid-term amendments.

Table II: Distribution fleet characteristics.

\begin{tabular}{|c|c|c|c|c|c|c|c|}
\hline \multicolumn{9}{|c|}{ Distribution fleet } \\
\hline \multirow{2}{*}{$\begin{array}{c}\text { Distribution } \\
\text { Node }\end{array}$} & \multirow{2}{*}{ Node } & \multicolumn{3}{|c|}{ Urban zone } & \multicolumn{3}{|c|}{ Peripheral zone } \\
\cline { 3 - 8 } & Orders & $\begin{array}{c}\text { Volume } \\
\left(\mathrm{m}^{3}\right)\end{array}$ & $\begin{array}{c}\text { Deliveries } \\
\text { per hour }\end{array}$ & Orders & $\begin{array}{c}\text { Volume } \\
\left(\mathrm{m}^{3}\right)\end{array}$ & $\begin{array}{c}\text { Deliveries } \\
\text { per hour }\end{array}$ \\
\hline DZ2 & TW6 & 180 & 3 & 20 to 35 & 100 & 3 & 8 to15 \\
\hline
\end{tabular}

Table III: Activities of each node type.

\begin{tabular}{|c|c|c|c|c|c|c|c|c|c|c|}
\hline \multirow[b]{2}{*}{$\begin{array}{c}\text { Distribution } \\
\text { zone }\end{array}$} & \multirow[b]{2}{*}{ Node } & \multirow[b]{2}{*}{$\begin{array}{c}\text { Dispatch } \\
\text { auxiliaries }\end{array}$} & \multicolumn{8}{|c|}{ Activities } \\
\hline & & & $\begin{array}{l}\text { Reception } \\
\text { and } \\
\text { classification }\end{array}$ & $\begin{array}{l}\text { Dispatch } \\
\text { process }\end{array}$ & $\begin{array}{c}\text { Shipping } \\
\text { and loading }\end{array}$ & $\begin{array}{c}\text { Claim } \\
\text { attention }\end{array}$ & $\begin{array}{c}\text { Fleet } \\
\text { coordination }\end{array}$ & $\begin{array}{c}\text { Supplier } \\
\text { surveillance }\end{array}$ & Payments & $\begin{array}{l}\text { Information } \\
\text { record }\end{array}$ \\
\hline \multirow{5}{*}{ DZ1 } & LC1 & $\mathrm{X}$ & $\mathrm{X}$ & $\mathrm{X}$ & $\mathrm{X}$ & $\mathrm{X}$ & $\mathrm{X}$ & $\mathrm{X}$ & $\mathrm{X}$ & $\mathrm{X}$ \\
\hline & TW1 & & $\mathrm{X}$ & & $\mathrm{X}$ & & & & & \\
\hline & TW2 & & $\mathrm{X}$ & & $\mathrm{X}$ & & & & & \\
\hline & TW3 & & $\mathrm{X}$ & & $\mathrm{X}$ & & & & & \\
\hline & TW4 & & $\mathrm{X}$ & & $\mathrm{X}$ & & & & & \\
\hline \multirow{3}{*}{ DZ2 } & LC2 & $\mathrm{X}$ & $\mathrm{X}$ & $\mathrm{X}$ & $\mathrm{X}$ & $\mathrm{X}$ & $\mathrm{X}$ & $\mathrm{X}$ & $\mathrm{X}$ & $\mathrm{X}$ \\
\hline & TW5 & & $\mathrm{X}$ & & $\mathrm{X}$ & & & & & \\
\hline & TW6 & & $\mathrm{X}$ & & $\mathrm{X}$ & & & & & \\
\hline \multirow{2}{*}{ DZ3 } & LC3 & $\mathrm{X}$ & $\mathrm{X}$ & $\mathrm{X}$ & $X$ & $\mathrm{X}$ & $\mathrm{X}$ & $\mathrm{X}$ & $\mathrm{X}$ & $\mathrm{X}$ \\
\hline & TW7 & & $\mathrm{X}$ & & $\mathrm{X}$ & & & & & \\
\hline \multirow{4}{*}{ DZ4 } & LC4 & $\mathrm{X}$ & $\mathrm{X}$ & $\mathrm{X}$ & $\mathrm{X}$ & $\mathrm{X}$ & $\mathrm{X}$ & $\mathrm{X}$ & $\mathrm{X}$ & $\mathrm{X}$ \\
\hline & TW8 & & $\mathrm{X}$ & & $\mathrm{X}$ & & & & & \\
\hline & TW9 & & $\mathrm{X}$ & & $\mathrm{X}$ & & & & & \\
\hline & TW10 & & $\mathrm{X}$ & & $\mathrm{X}$ & & & & & \\
\hline
\end{tabular}

\section{SIMULATION MODEL}

The model has been developed using the VenSim ${ }^{\circledR}$ DSS system dynamics software and is arranged into three submodels with their respective flow diagrams: DC, definition of node type and DZs. The DC's sub model provides details of the variables which imply carrying out all the activities directly relating to processing weekly orders, ranging from ordering items and materials to preparing and dispatching orders. The Warehouse, Picking and Dispatching Areas contemplate rates of performance, execution times, the working journeys required and personnel's requirements.

The distribution node type submodel consists in determining the node type to deal with distribution route demand by assessing the qualitative and quantitative variables, whose weighting enables a score to be given to the facilities covering the demand points in a DZ. The highest score is given by the TW category to be installed in this node; in this way, the remaining nodes will have a TW. This allocation helps establish the distribution node type in the long term because variables do not change in the short- or mid-term. If a considerable change is made, it is done in the long term in order to reconsider alternatives. Table IV provides details of the variables employed and their respective information.

The DZs submodel presents the volume that each DZ processes with the respective LCs and TWs. In general terms, the Operational Area requirements, personnel requirements and the distribution fleet which each node requires are considered. In the Operational Area, the 
space needed to carry out the dispatching process is contemplated; that is, the surface area to locate and classify orders, internal transit, dock areas and work stations. Apart from the quantity of auxiliaries, personnel requirements include activity rates and the work journeys required during each period. Finally, the number of vehicles for distribution to urban and peripheral zones is considered in the distribution fleet, along with delivery rates, the cubic capacity loading requirement, use of the fleet, distribution times, and depending on these times, the extent to which deliveries are fulfilled in a schedule and, therefore, the system's service level.

Table IV: Variables considered for the definition of node type.

\begin{tabular}{|c|c|c|c|c|c|}
\hline \multirow{2}{*}{ Variables } & \multicolumn{2}{|c|}{ Type } & Maximum & \multicolumn{2}{c|}{ Weights } \\
\cline { 2 - 3 } \cline { 5 - 6 } & Quantitative & Qualitative & score & Score & Percentage \\
\hline Security factor & & $\mathrm{X}$ & 5.00 & 1.25 & $25 \%$ \\
\hline $\begin{array}{c}\text { Road access } \\
\text { factor }\end{array}$ & & $\mathrm{X}$ & 5.00 & 0.75 & $15 \%$ \\
\hline Distance factor & $\mathrm{X}$ & & 5.00 & 0.75 & $15 \%$ \\
\hline Demand factor & $\mathrm{X}$ & & 5.00 & 2.25 & $45 \%$ \\
\hline \multicolumn{2}{|l}{} & Total & 5.00 & $100 \%$ \\
\hline
\end{tabular}

\section{EVALUATION OF THE RESULTS}

The simulation results for a simulated time horizon of 260 weekly periods generally presents the following aspects:

Demand level, and its expected behaviour, which is processed throughout the simulation horizon (Fig. 3). The distribution system is composed of the distribution nodes and types forming the network, the complete distribution fleet as specified per urban and peripheral dispatching zone, the complete Operational Area required for the dispatching process and all the dispatch personnel which the system relies on in all the DZs (Table V).

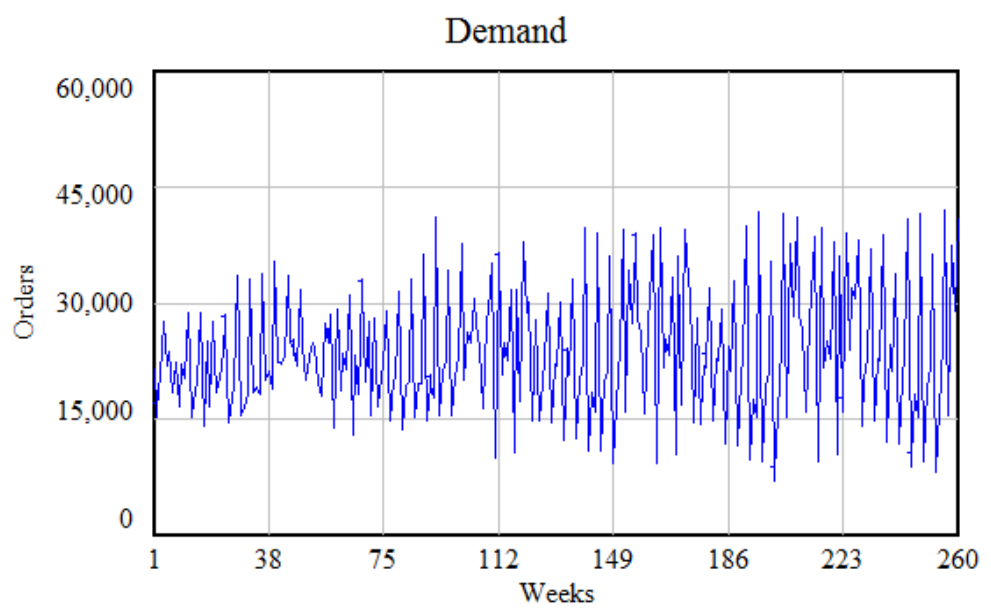

Orders: Simulation1

Figure 3: Demand variation.

The requirements of the Operational Area; that is, the surface area needed to cover the demand level in the simulation horizon. To calculate this requirement, the Placement order area, the Placement order sites, the Internal and external aisle areas, the Dock area and the Workstation area are all considered. The operational area per DZ and its respective participation in the system are shown (Table VI). 
Table V: Composition of the distribution system.

\begin{tabular}{|l|c|c|c|c|c|c|}
\hline \multicolumn{9}{|c|}{ Distribution network size } \\
\hline \multirow{2}{*}{ Description } & Number & $\begin{array}{c}\text { Operational } \\
\text { area }\left(\mathrm{m}^{2}\right)\end{array}$ & Personnel & Urban zone & $\begin{array}{c}\text { Peripheral } \\
\text { zone }\end{array}$ & Total \\
\hline Distribution zones & 5 & & & & & \\
\hline Distribution nodes & 15 & & & & & \\
\hline Distribution centre & 1 & 2,560 & 16 & 71 & 129 & 200 \\
\hline Logistic centres & 4 & & & & & \\
\hline Transit warehouses & 10 & & & & & \\
\hline
\end{tabular}

Table VI: Required operational area per distribution zone.

\begin{tabular}{|c|c|c|c|c|}
\hline \multirow{2}{*}{ Distribution zones } & \multirow{2}{*}{ Nodes } & \multicolumn{3}{|c|}{ Required operational area $\left(\mathrm{m}^{2}\right)$} \\
\hline & & Year1 & Total & Percentage \\
\hline \multirow{5}{*}{ Zone1 } & LC1 & 371 & \multirow{5}{*}{850} & \multirow{5}{*}{$33 \%$} \\
\hline & TW1 & 72 & & \\
\hline & TW2 & 95 & & \\
\hline & TW3 & 101 & & \\
\hline & TW4 & 88 & & \\
\hline \multirow{3}{*}{ Zone2 } & LC2 & 151 & \multirow{3}{*}{430} & \multirow{3}{*}{$17 \%$} \\
\hline & TW5 & 77 & & \\
\hline & TW6 & 83 & & \\
\hline \multirow{2}{*}{ Zone3 } & LC3 & 89 & \multirow{2}{*}{200} & \multirow{2}{*}{$8 \%$} \\
\hline & TW7 & 58 & & \\
\hline \multirow{4}{*}{ Zone4 } & LC4 & 106 & \multirow{4}{*}{460} & \multirow{4}{*}{$18 \%$} \\
\hline & TW8 & 121 & & \\
\hline & TW9 & 68 & & \\
\hline & TW10 & 71 & & \\
\hline Zone5 & DC & 602 & 620 & $24 \%$ \\
\hline & & & 2,560 & $100 \%$ \\
\hline
\end{tabular}

The distribution fleet is provided and shows the number of vehicles allocated to each urban and peripheral DZ. Furthermore, the distribution fleet per DZ and the participation of each one in relation to the network in general are also indicated (Table VII).

The personnel in the DZ should have the DC and the LCs to carry out the operational and back office activities, respectively (Fig. 4 and Table VIII).

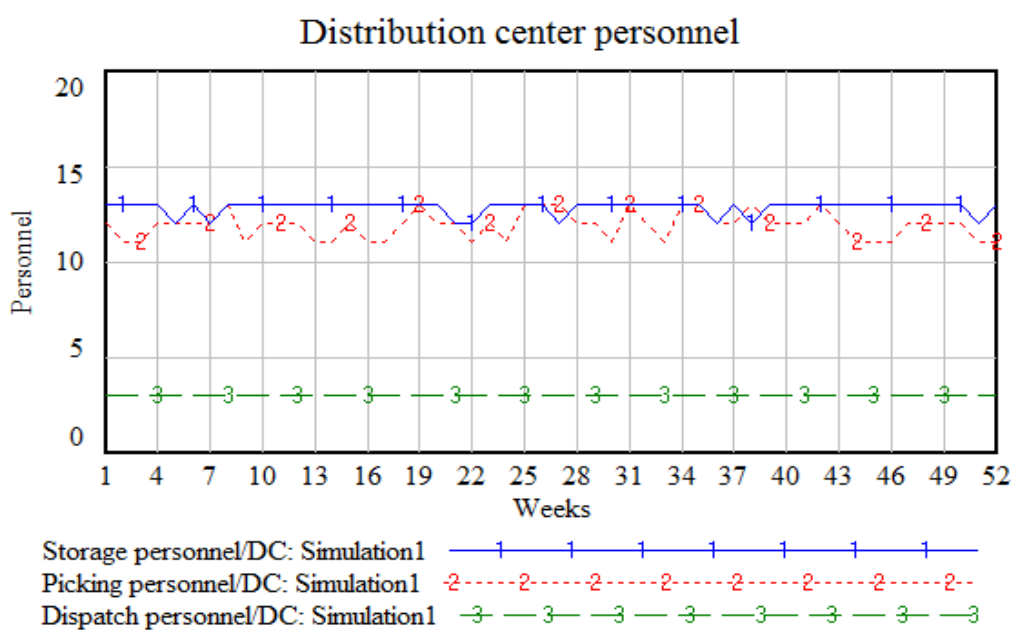

Figure 4: Distribution centre's personnel. 
Operational activities are related directly with the distribution process. Back office activities do not relate directly with the distribution process, but actually derive from it; for instance, paying distribution suppliers, reporting distribution and delivery times, and dealing with claims, among others.

The information offered in Table IX results from the distribution node type definition, which is defined in the model in accordance with the variables set out in Table IV of the Simulation Model Section. As previously mentioned, this is a long-term definition which allows to know its prolongation and at what time a change in facilities is to be considered in accordance with the volume of orders to be processed, Demand of the zone, as well as the Security and route access factors considered, and each one with the respective weighting of its specific score.

Table VII: Initial distribution fleet per distribution zone.

\begin{tabular}{|c|c|c|c|c|c|}
\hline \multirow{2}{*}{$\begin{array}{l}\text { Distribution } \\
\text { zones }\end{array}$} & \multirow{2}{*}{ Nodes } & \multicolumn{4}{|c|}{ Distribution fleet } \\
\hline & & Urban zone & Peripheral zone & Total & Percentage \\
\hline \multirow{5}{*}{ Zone 1} & LC1 & 21 & 19 & \multirow{5}{*}{73} & \multirow{5}{*}{$34 \%$} \\
\hline & TW1 & 1 & 5 & & \\
\hline & TW2 & 1 & 8 & & \\
\hline & TW3 & 2 & 9 & & \\
\hline & TW4 & 1 & 6 & & \\
\hline \multirow{3}{*}{ Zone 2} & LC2 & 4 & 12 & \multirow{3}{*}{30} & \multirow{3}{*}{$14 \%$} \\
\hline & TW5 & 1 & 6 & & \\
\hline & TW6 & 1 & 6 & & \\
\hline \multirow{2}{*}{ Zone 3} & LC3 & 2 & 6 & \multirow{2}{*}{13} & \multirow{2}{*}{$6 \%$} \\
\hline & TW7 & 1 & 4 & & \\
\hline \multirow{4}{*}{ Zone 4} & LC4 & 3 & 7 & \multirow{4}{*}{34} & \multirow{4}{*}{$16 \%$} \\
\hline & TW8 & 3 & 7 & & \\
\hline & TW9 & 1 & 6 & & \\
\hline & TW10 & 1 & 6 & & \\
\hline Zone 5 & $\mathrm{DC}$ & 23 & 43 & 66 & $31 \%$ \\
\hline & & 66 & 150 & 216 & $100 \%$ \\
\hline
\end{tabular}

Table VIII: Dispatch personnel allocated to distribution zones.

\begin{tabular}{|c|c|c|c|}
\hline \multirow{2}{*}{$\begin{array}{l}\text { Distribution } \\
\text { zones }\end{array}$} & \multirow{2}{*}{ Nodes } & \multicolumn{2}{|c|}{ Dispatch personnel } \\
\hline & & Year 1 & Percentage \\
\hline \multirow{5}{*}{ Zone 1} & $\mathrm{LC} 1$ & \multirow{5}{*}{4} & \multirow{5}{*}{$25 \%$} \\
\hline & TW1 & & \\
\hline & TW2 & & \\
\hline & TW3 & & \\
\hline & TW4 & & \\
\hline \multirow{3}{*}{ Zone 2} & LC2 & \multirow{3}{*}{1} & \multirow{3}{*}{$6 \%$} \\
\hline & TW5 & & \\
\hline & TW6 & & \\
\hline \multirow{2}{*}{ Zone 3} & LC3 & \multirow{2}{*}{1} & \multirow{2}{*}{$6 \%$} \\
\hline & TW7 & & \\
\hline \multirow{4}{*}{ Zone 4} & LC4 & \multirow{4}{*}{1} & \multirow{4}{*}{$6 \%$} \\
\hline & TW8 & & \\
\hline & TW9 & & \\
\hline & TW10 & & \\
\hline Zone 5 & $\mathrm{DC}$ & 9 & $56 \%$ \\
\hline
\end{tabular}


Table IX: Allocation results of node type per distribution zone.

\begin{tabular}{|c|c|c|c|c|c|c|c|c|c|c|c|c|c|c|}
\hline & \multicolumn{14}{|c|}{ Distribution zones } \\
\hline & \multicolumn{5}{|c|}{ Zone 1} & \multicolumn{3}{|c|}{ Zone 2} & \multicolumn{2}{|c|}{ Zone 3} & \multicolumn{4}{|c|}{ Zone 4} \\
\hline & DR1 & DR2 & DR3 & DR4 & DR5 & DR6 & DR7 & DR8 & DR9 & DR10 & DR11 & DR12 & DR13 & DR14 \\
\hline Score & 3.6 & 2.1 & 2.2 & 2.3 & 2.1 & 2.9 & 2.5 & 2.6 & 2.7 & 2.1 & 2.9 & 2.0 & 2.0 & 1.6 \\
\hline Allocation & $\mathrm{LC}$ & TW & TW & TW & TW & LC & TW & TW & LC & TW & $\mathrm{LC}$ & TW & TW & TW \\
\hline
\end{tabular}

Table $\mathrm{X}$ shows the definitions relating to the total activity rates and the dispatch auxiliaries required, and to the time used in each available Journey. Each node has fixed personnel allocated. Nevertheless, depending on the demand level to be processed during each period, more auxiliary personnel may be required. The total time required (hours) for order processing is also shown in accordance with the total activity rate, which indicates the proportion of the journey used for this task.

Table X: Personnel requirements and activity rates.

\begin{tabular}{|c|c|c|c|c|}
\hline \multirow{6}{*}{ Zone 1} & Distribution zones & \multicolumn{2}{|c|}{ Period } & \multirow{2}{*}{ Increase } \\
\hline & LC1 & Low & High & \\
\hline & Fixed Personnel & 2 & & \\
\hline & Orders & 3186 & 8476 & $166 \%$ \\
\hline & Total activity rate & 400 & 800 & $100 \%$ \\
\hline & Personnel required & 2 & 4 & $100 \%$ \\
\hline \multirow[t]{5}{*}{ Zone 2} & LC2 & & & \\
\hline & Fixed Personnel & 1 & & \\
\hline & Orders & 853 & 2159 & $153 \%$ \\
\hline & Total activity rate & 200 & 400 & $100 \%$ \\
\hline & Personnel required & 1 & 2 & $100 \%$ \\
\hline \multirow[t]{9}{*}{ Zone 3} & LC3 & & & \\
\hline & Fixed Personnel & 1 & & \\
\hline & Orders & 474 & 1033 & $118 \%$ \\
\hline & Total activity rate & 200 & 200 & $0 \%$ \\
\hline & Personnel required & 1 & 1 & $0 \%$ \\
\hline & Required time (hours) & 2.4 & 5.2 & \\
\hline & Total activity rate & 200 & 400 & $100 \%$ \\
\hline & Personnel required & 1 & 2 & $100 \%$ \\
\hline & Required time (hours) & 2.4 & 2.6 & \\
\hline \multirow[t]{9}{*}{ Zone 4} & $\mathrm{LC} 4$ & & & \\
\hline & Fixed Personnel & 1 & & \\
\hline & Orders & 610 & 1291 & $112 \%$ \\
\hline & Total activity rate & 200 & 200 & $0 \%$ \\
\hline & Personnel required & 1 & 1 & $0 \%$ \\
\hline & Required time (hours) & 3.1 & 6.5 & \\
\hline & Total activity rate & 200 & 400 & $100 \%$ \\
\hline & Personnel required & 1 & 2 & $100 \%$ \\
\hline & Required time (hours) & 3.1 & 3.2 & \\
\hline
\end{tabular}

Finally, Fig. 5 and Table XI present details of the distribution times employed during the distribution journey. Firstly, the graph is provided which takes, for example, four periods of the urban delivery zone of node CL1, where the start and end times of the distribution journey are indicated, along with the deadline for deliveries, respectively.

The developed simulation model allows the preparation of a reference conceptual model to define the LCs and TWs in the distribution network specifically for the supply chain under study. However, it can also serve as a reference for other supply chains with similar characteristics. This conceptual model is presented by schematising the process inputs and 
outputs in which the distribution nodes intervene, and also includes the generic process objectives and indicators. The conceptual model covers all the aspects and variables with which the system is represented, and they are schematically presented in Fig. 6.

Firstly, the process inputs are presented, which are demand from clients and the distribution network which, for the purpose of this model, details the structural and qualitative aspects considered when defining the networks' LCs and TWs. Next, the processes, subprocesses and the most relevant information processed in each node type are mentioned. Hence, the outputs obtained from the previously presented processes are offered, which consider both the operational and back office activities undertaken in the LC-type nodes, as appropriate. Finally, this model includes the objectives and indicators to guide and control the system nodes' performance.

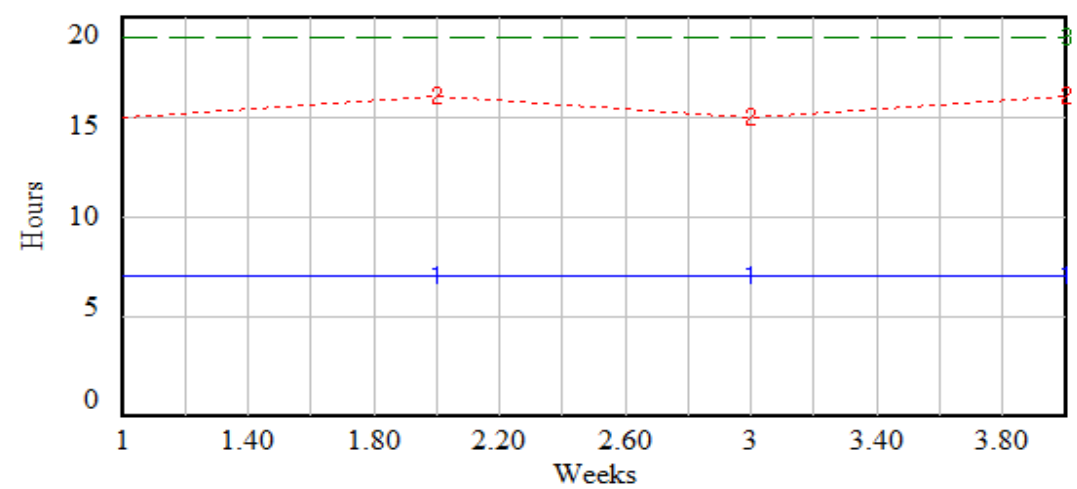

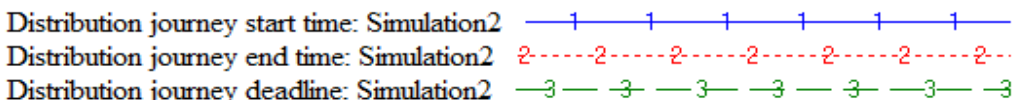

Figure 5: Distribution journey of the LC1 urban zone fleet.

Table XI: Distribution time of the node LC1 fleet.

\begin{tabular}{|l|c|c|c|c|}
\hline \multirow{2}{*}{ Description } & \multicolumn{5}{|c|}{ LC1 distribution fleet } \\
\cline { 2 - 6 } & \multicolumn{2}{|c|}{ Urban zone } & \multicolumn{2}{|c|}{ Peripheral zone } \\
\hline Start time & 7 & & 6 & \\
\hline Travel time & 1 & $13 \%$ & 6 & $55 \%$ \\
\hline Effective distribution time & 7 & $88 \%$ & 5 & $45 \%$ \\
\hline Journey duration & 8 & & 11 & \\
\hline Deadline & 19 & & 19 & \\
\hline Difference in time window for distribution & 4 & & 2 & \\
\hline Order delivery rate & 23 & & 13 & \\
\hline Utilisation of loading capacity & $144 \%$ & & $61 \%$ & \\
\hline Average orders per vehicle & 178 & & 75 & \\
\hline Average & 160 & & 70 & \\
\hline
\end{tabular}

A significant contribution to the Distribution Area stems from the simulation model, which consists in developing a specific reference conceptual model for the supply chain that is the object of this study. However it can be extended to other supply chains, including the parameters considered to define a node within the system. The reference model is used from the process viewpoint in which one of the inputs is the distribution network nodes. In this instance, details of the considered structural and qualitative aspects are provided. Next, the processes and sub-processes developed in the network's LCs and TWs are indicated and the outputs obtained in each node are mentioned, which are of the operational and back-office type. Moreover, the objectives pursued in the chain's distribution system and the aspects on which the respective measurements and controls must be made are also included. This model is a formal tool to support decision making in supply chains in this particular field. 


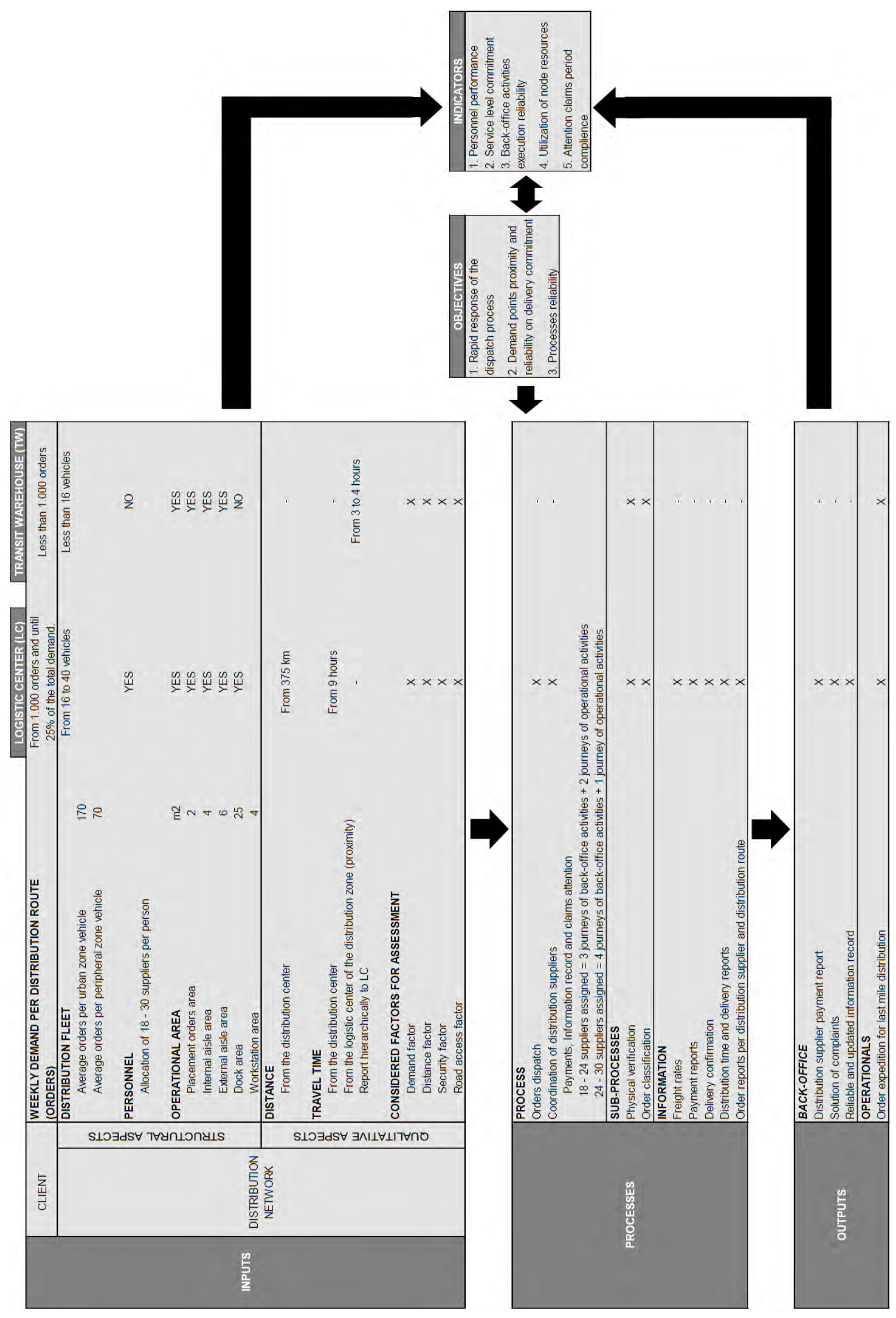

Figure 6: Reference model to define the LCs and TWs in the distribution network. 
The simulation model can be downloaded as a published version at: http://www.cigip.upv.es/docs/2013IJOSMDiezMulaCampuzano.vpm.

\section{CONCLUSIONS}

This work stems from a real direct sale cosmetics supply chain context. The proposed systems dynamics simulation model represents the operation of a distribution network. It includes activity rates and times to do tasks, and allocates resources such as distribution fleet and operational personnel. A series of parameters has been determined to define distribution node type in order to provide a reference conceptual model that can be applied in the supply chain under study and in others with similar characteristics. This model offers a good understanding of how a distribution network operates in order to: determine its structure and size, know its behaviour and evolution, assess its type of facilities, and analyse and define the network's current and future requirements, among others, from the data on variables like demand level, distribution times, distribution fleet capacity, resources allocation, and the rates of activity and performance of the various activities involved in the distribution process.

The simulation model is run using systems dynamics for the distribution network of a direct sale supply chain of cosmetics and hygiene products and it represents the operation of the distribution system as a whole by including the following variables: the infrastructure, resources and activities of the distribution nodes. The model structure helps learn about the operational volume being processed in each node, the times required for the respective activities and the resources that must be allocated to fulfil the chain's strategic objective. Furthermore, this structure permits the analysis of various scenarios that may be presented in the distribution system, leading to the definition and size of network nodes.

Finally, this work offers a new application of the system dynamics modelling approach to a real supply chain management problem. In this manner, emphasising supply chain simulation case studies through systems dynamics models to improve performance is suggested.

\section{ACKNOWLEDGMENT}

This work has been funded by the UPV project entitled 'Material Requirement Planning Fourth Generation (MRPIV)' (Ref. PAID-05-12).

\section{REFERENCES}

[1] Lambert, D. M.; Cooper, M. C. (2000). Issues in supply chain management, Industrial Marketing Management, Vol. 29, No. 1, 65-83, doi:10.1016/S0019-8501(99)00113-3

[2] Forrester, J. W. (1961). Industrial Dynamics, M.I.T Press, Waltham, Massachusetts

[3] Sterman, J. D. (2000). Business Dynamics: Systems Thinking and Modeling for a Complex World, Irwin-McGraw Hill, Boston

[4] Klose, A.; Drexl, A. (2005). Facility location models for distribution system design, European Journal of Operational Research, Vol. 162, No. 1, 4-29, doi:10.1016/j.ejor.2003.10.031

[5] Beamon, B. M. (1998). Supply chain design and analysis: Models and methods, International Journal of Production Economics, Vol. 55, No. 3, 281-294, doi:10.1016/S0925-5273(98)00079-6

[6] Stadtler, H.; Kilger, C. (2008). Supply Chain Management and Advanced Planning: Concepts, Models, Software, and Case Studies, Springer, Berlin

[7] Archibald, G.; Karabakal, N.; Karlsson, P. (1999). Supply chain vs. supply chain: using simulation to compete beyond the four walls, Proceedings of the 1999 Winter Simulation Conference, Vol. 2, 1207-1214 
[8] Chang, Y.; Makatsoris, H. (2001). Supply chain modeling using simulation, International Journal of Simulation: System, Science and Technology, Vol. 2, No. 1, 24-30

[9] Banks, J.; Buckley, S.; Jain, S.; Lendermann, P. (2002). Panel session: Opportunities for simulation in supply chain management, Proceedings of the 2002 Winter Simulation Conference, $1652-1658$

[10] Terzi, S.; Cavalieri, S. (2004). Simulation in the supply chain context: a survey, Computers in Industry, Vol. 53, No. 1, 3-16, doi:10.1016/S0166-3615(03)00104-0

[11] Carson, J. (2003) Introduction to modelling and simulation, Proceedings of the 2003 Winter Simulation Conference, Vol. 1, 7-13

[12] Cannella, S.; Povoa, A. P.; Framinan, J. M.; Relvas, S. (2012). Metrics for bullwhip effect analysis, Journal of the Operational Research Society, Vol. 64, 1-16, doi:10.1057/jors.2011.139

[13] Cannella, S.; Ciancimino, E.; Framinan, J. M. (2011). Inventory policies and information sharing in multi-echelon supply chains, Production Planning \& Control, Vol. 22, No. 7, 649-659, doi:10.1080/09537287.2010.512276

[14] Ciancimino, E.; Cannella, S.; Bruccoleri, M.; Framinan, J. M. (2012). On the bullwhip avoidance phase: the synchronised supply chain, European Journal of Operational Research, Vol. 221, No. 1, 49-63, doi:10.1016/j.ejor.2012.02.039

[15] Cannella, S.; Ciancimino, E. (2010). On the bullwhip avoidance phase: supply chain collaboration and order smoothing, International Journal of Production Research, Vol. 48, No. 22, 6739-6776, doi:10.1080/00207540903252308

[16] Rabelo, L.; Helal, M.; Jones, A.; Min, H.-S. (2005). Enterprise simulation: a hybrid system approach, International Journal of Computer Integrated Manufacturing, Vol. 18, No. 6, 498-508, doi:10.1080/09511920400030138

[17] Lim, H.; Shiode, N. (2011). The impact of online shopping demand on physical distribution networks: a simulation approach, International Journal of Physical Distribution \& Logistics Management, Vol. 41, No. 8, 732-749, doi:10.1108/09600031111166401

[18] Bozickovic, R.; Radosevic, M.; Cosic, I.; Sokovic, M.; Rikalovic, A. (2012). Integration of Simulation and Lean Tools in Effective Production Systems - Case Study, Strojniski vestnik Journal of Mechanical Engineering, Vol. 58, No. 11, 642-652, doi:10.5545/sv-jme.2012.387

[19] Calderón, J. L.; Lario, F. C. (2007). Simulación de cadenas de suministro: Nuevas aplicaciones y áreas de desarrollo, Información Tecnológica, Vol. 18, No. 1, 137-146, doi:10.4067/S071807642007000100018

[20] Gary, M. S.; Kunc, M.; Morecroft, J. D. W., Rockart, S. F. (2008). System Dynamics and Strategy, System Dynamics Review, Vol. 24, No. 4, 407-429, doi:10.1002/sdr.402

[21] Campuzano, F.; Mula, J.; Peidro, D. (2010). Fuzzy estimations and system dynamics for improving supply chains, Fuzzy Sets and Systems, Vol. 161, No. 11, 1530-1542, doi:10.1016/ j.fss.2009.12.002

[22] Campuzano, F.; Mula, J. (2011). Supply chain simulation: A system dynamics approach for improving performance, Springer, London

[23] Khaji, M. R.; Shafaei, R. (2011). A system dynamics approach for strategic partnering in supply networks, International Journal of Computer Integrated Manufacturing, Vol. 24, No. 2, 106-125, doi:10.1080/0951192X.2010.531288

[24] Persson, F.; Araldi, M. (2009). The development of a dynamic supply chain analysis tool Integration of SCOR and discrete event simulation, International Journal of Production Economics, Vol. 121, No. 2, 574-583, doi:10.1016/j.ijpe.2006.12.064

[25] Disney, S. M.; Naim, M. M.; Potter, A. (2004). Assessing the impact of e-business on supply chain dynamics, International Journal of Production Economics, Vol. 89, No. 2, 109-118, doi:10.1016/S0925-5273(02)00464-4

[26] Bronja, H. (2011). Multi-criteria approach to ranking suppliers in the supply chain concept, Technical Gazette, Vol. 18, No. 3, 393-401

[27] Hwang, H. S. (2002). Design of supply-chain logistics system considering service level, Computers \& Industrial Engineering, Vol. 43, No. 1-2, 283-297, doi:10.1016/S03608352(02)00075-X 